\title{
Design and Simulation of Permanent Magnet Synchronous Generators for Small Scale Wind Power Plants
}

\author{
Amir Hamzah ${ }^{1 *}$, Suwitno Suwitno ${ }^{1}$, Joni $\operatorname{Irfan}^{1}$, Iwan Kurniawan ${ }^{2}$, Haji Gussyafri ${ }^{3}$, \\ Herry Susanto ${ }^{4}$, and Turkadze Tsitsino ${ }^{5}$ \\ ${ }^{1}$ Department of Electrical Engineering, Universitas Riau, Kampus Bina Widya, \\ Simpang Baru, Pekanbaru, 28293 Indonesia \\ ${ }^{2}$ Department of Mechanical Engineering, Universitas Riau, Kampus Bina Widya, \\ Simpang Baru, Pekanbaru, 28293 Indonesia \\ ${ }^{3}$ Department of Civil Engineering, Universitas Riau, Kampus Bina Widya, \\ Simpang Baru, Pekanbaru, 28293 Indonesia \\ ${ }^{4}$ Graduate School of Renewable Energy, Darma Persada University, \\ Jl. Taman Malaka Selatan No.22, Jakarta Timur, 13450, Indonesia \\ ${ }^{5}$ Department of Chemical and Environmental Technologies, Akaki Tsereteli State University, \\ 59 Tamar mepe str., Kutaisi 4600, Georgia
}

\begin{abstract}
Wind energy is one of the primary energy sources that can be used to produce electricity. Indonesia has the potential to harness wind energy to produce electricity due to located on the equator, especially in coastal areas. An alternative to the availability of electricity in remote coastal areas is to use small-scale wind power plants. One component that plays an important role in wind power generation systems is the generator. A generator is a machine that converts mechanical energy into electrical energy. In small scale wind power plants, permanent magnet synchronous generators (PMSG) are commonly used as energy conversion machines. In this paper, a PMSG has been designed for small-scale and low-speed wind power generation as an energy conversion machine. PMSG which has been designed has the following specifications: $500 \mathrm{~W}$, three phases, 18 slots, 12 poles, with a rotation speed of $500 \mathrm{rpm}$. The simulation test results obtained the following data, the output phase-phase maximum voltage of the generator is $38.84 \mathrm{~V}$, and phase maximum voltage is $22.5 \mathrm{~V}$.
\end{abstract}

Keywords: Coastal area, low speed, small scale generator, renewable energy, wind energy

\section{Introduction}

Wind energy is one of the primary energy sources that can be used to produce electricity. Wind energy is a safe, clean and abundant source of energy. Wind energy is processed by

\footnotetext{
* Corresponding author: amir.hamzah@eng.unri.ac.id
} 
wind turbines into power, which in mathematical equation is a multiplication function of the wind capture area, turbine performance coefficient, air density and wind speed. In a wind energy conversion system (WECS), wind energy is captured by wind turbines which are then converted into electrical energy using generators. WECS is a complex system, which includes several scientific fields which include the concepts of aerodynamic and mechanical forms, control and electrical engineering. WECS is a combination of wind turbines, electric generators, power electronics and control systems.

In general, there are two types of wind turbines that are widely used in wind power generation, horizontal axis wind turbine types and vertical axis wind turbines. Wind power plant is a system that consists of several component parts. Each component has a different function. One component is a generator. A generator is a machine that converts mechanical energy into electrical energy. The generator discussed in this paper is a permanent magnet synchronous generator. Permanent synchronous magnetic generator (PMSG), has advantages compared to other types of generators. The advantages are not too noisy, high efficiency and have a long service life. Various designs of permanent-magnet synchronous wind generators have been carried out [1-8]. In addition, researchers also have done a lot of control and converter to obtain results that can be utilized in renewable energy power generation applications [9-12].

\section{System description}

Synchronous machines are alternating current electric machines that work or function as generators or as motors. When working as a generator, to get a stable frequency, rotation must be fixed, while as a motor, supplied by the grid with a fixed frequency. Synchronous or synchronous machines are electric machines that require a fixed frequency and rotation.

The principle of generating synchronous generators is the same as direct current generators, with electromagnetic induction. In the generator there is an electromagnetic induction which refers to Faraday and Lenz's law. Faraday's Law explains that a change in the magnetic flux surrounding a coil will cause an induced emf at the ends of the coil. While Lenz's law explains that the induced emf that appears directed towards changing flux causes a current to flow or in other words the induced current produces a magnetic field that opposes the change in the magnetic flux that produces an induced current. The permanent magnet synchronous generator works using an excitation field generated from a permanent magnet, not from a coil. Then, that the magnetic flux is produced by a permanent magnetic field.

\subsection{Design methodology}

The purpose of this paper is to obtain a low-speed PMSG design for small-scale wind power applications. PMSG with low speed is expected not to use gearboxes in its operation therefore, production costs can be minimized. In addition, it can also be used in locations with low wind speeds. The permanent magnet synchronous generator design is made with $500 \mathrm{~W}$ of power. PMSG has an initial design with a number of slots on the stator 18 . This amount is obtained from PMSG that has been commercialized in the market. The development of the design is done on the number of poles, by making PMSG poles to 12 poles. Thus, in the rotor there are 12 magnetic poles or six pairs of north and south poles. 


\subsection{Dimensions and material of permanent magnet synchronous generators}

Parameters and design criteria data used to determine the design of a three phase permanent magnet synchronous generator, as shown in Table 1. Stator and rotor design specification data from a three phase PMSG, 18 slots 12 poles, as shown in Table 2. All data specifications and parameters then made a design framework using CAD software (trial edition). CAD is software commonly used to design $2 \mathrm{D}$ parts with more accurate accuracy. Files that have been created are saved in the .dxf format in the CAD software. Furthermore, the file will be imported into MagNet Infolytica software. This generator uses a combination of 18 slots and 12 poles. The appearance of the generator design is shown in Figure 1. For further information from each component forming the generator design is explained in Figure 2.

Table 1. Input parameter.

\begin{tabular}{|c|c|}
\hline Parameter & Value \\
\hline Rated power $(\mathrm{W})$ & 500 \\
\hline Voltage per phase (V) & 24 \\
\hline Phase number & 3 \\
\hline Number of stator slots & 18 \\
\hline Number of magnet poles & 12 \\
\hline Frequency (Hz) & 50 \\
\hline Speed (rpm) $1 \mathrm{rpm}=1 / 60 \mathrm{~Hz}$ & 500 \\
\hline Power factor & 0.85 \\
\hline
\end{tabular}

Table 2. Estimated of hydropower plant type and total hydropower output.

\begin{tabular}{|c|c|c|c|}
\hline No & Dimension & Unit & Value \\
\hline 1 & Stator outer diameter & $\mathrm{mm}$ & 175 \\
\hline 2 & Stator inner diameter & $\mathrm{mm}$ & 116 \\
\hline 3 & Rotor diameter & $\mathrm{mm}$ & 114 \\
\hline 4 & Diameter of inner slots & $\mathrm{mm}$ & 159 \\
\hline 5 & Diameter of inner magnet & $\mathrm{mm}$ & 109 \\
\hline 6 & Diameter of outer magnet & $\mathrm{mm}$ & 110.5 \\
\hline 7 & Stator/Rotor core thickness & $\mathrm{mm}$ & 45 \\
\hline 8 & Magnet length & $\mathrm{mm}$ & 45 \\
\hline 9 & Magnet thickness & $\mathrm{mm}$ & 18 \\
\hline 10 & Umbrella high & $\mathrm{mm}$ & 20 \\
\hline 11 & Teeth width & $\mathrm{mm}$ & 8.8 \\
\hline 12 & Airgap length & $\mathrm{mm}$ & 1 \\
\hline
\end{tabular}




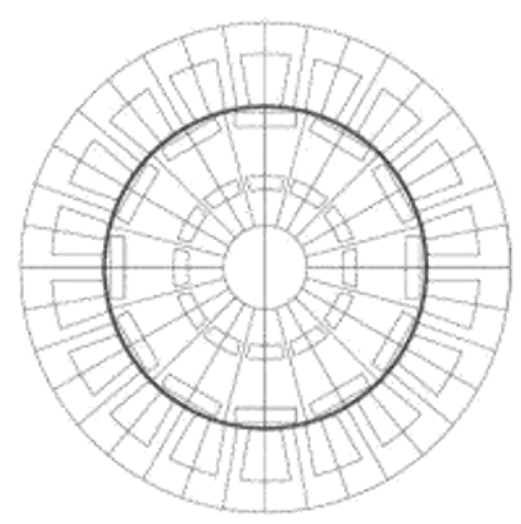

Fig. 1. 2D permanent magnet synchronous generator design.

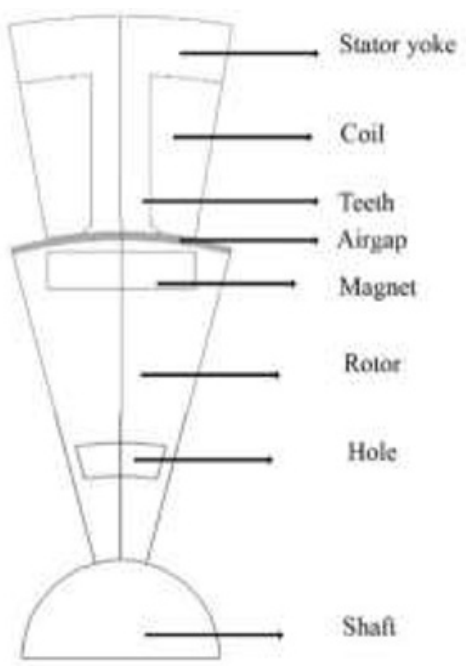

Fig. 2. Detail of generator components.

Generator core lamination material is made of steel with a type of silicon steel, in software, type M250 - 50A magnet. This type of material is used on the sides of the rotor and stator. In the rotor, it is used as a location for permanent magnets and connected to the shaft. The stator is used for forming stator winding slots. The nature of this material has magnetic characteristics, if subject to magnetic force. This material has a silicon content of approximately $0.5 \%$ to $3.25 \%$. The presence of this silicon in steel can increase the volume of resistivity to reduce eddy currents and reduce hysteresis. The permanent magnet material used in this design is the neodymium $\mathrm{NdFeB}$ type 48/11. Furthermore, for windings using type Copper $5.77 \mathrm{e} 7 \mathrm{~S} \mathrm{~m}^{-1}$.

\section{Results and discussions}

The generator design has been initialized material in MagNet software, as shown in Figure 3. The PMSG is simulated under load and not load conditions. The simulation circuit form of permanent magnet synchronous 18 slot 12 pole generator is shown in Figure 4 and Figure 5. In a load simulation circuit, the generator output will be rectified and 
connected to the $\mathrm{R}$ load. The calculation of the rotational speed of degrees per second, to form a wave obtained from the number of rotor rotation degrees divided by the number of pairs of poles. So that in this design obtained a rotation of $360 \%=60 \%$. In simulation, several variations of the speed of the generator has been done. The parameters set in this simulation are the rotor angle speed $(\omega)$ and time. The variation of speed that will be simulated is the speed of $100 \mathrm{rpm}, 200 \mathrm{rpm}, 300 \mathrm{rpm}, 400 \mathrm{rpm}$ and $500 \mathrm{rpm}(1 \mathrm{rpm}=$ $1 / 60 \mathrm{~Hz})$

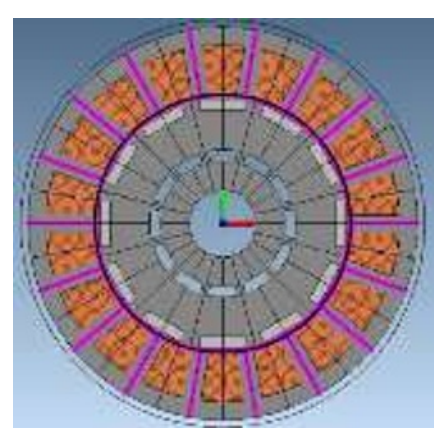

Fig. 3. Geometry model of permanent magnet synchronous generator.

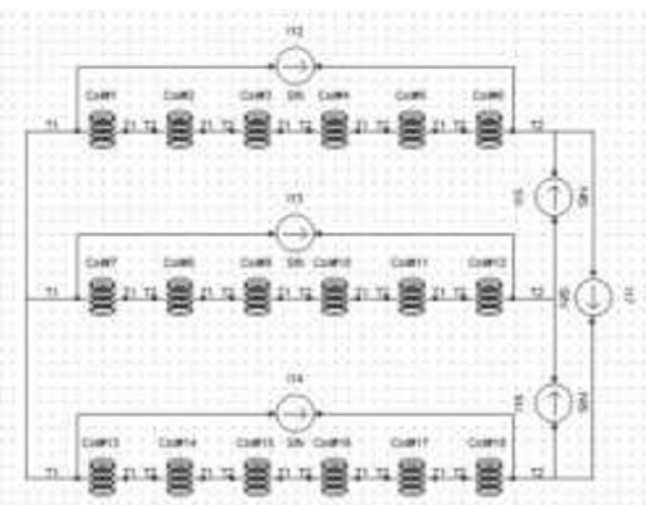

Fig. 4. No load PMSG simulation circuit.

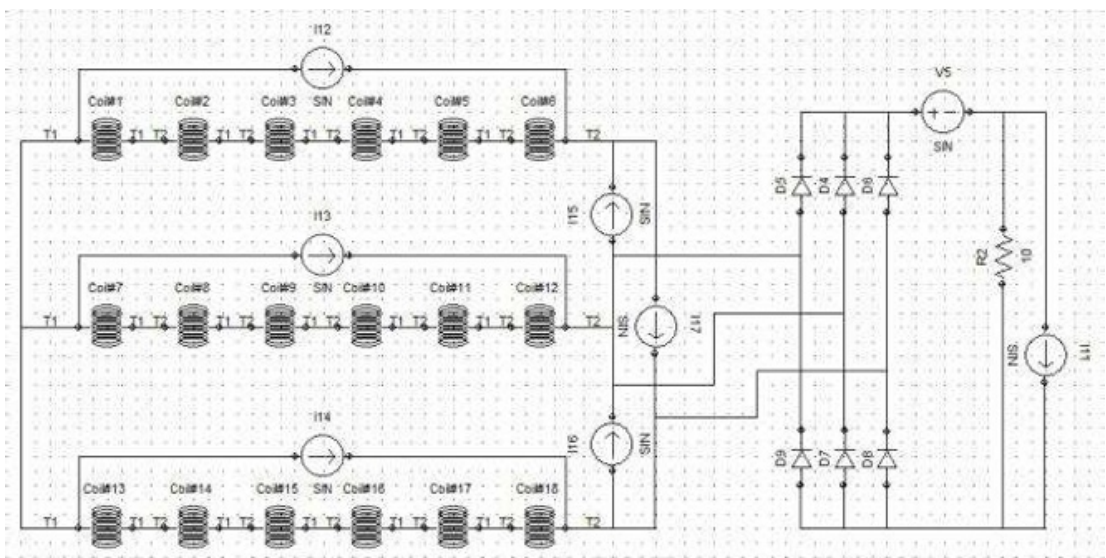

Fig. 5. Load PMSG simulation circuit. 


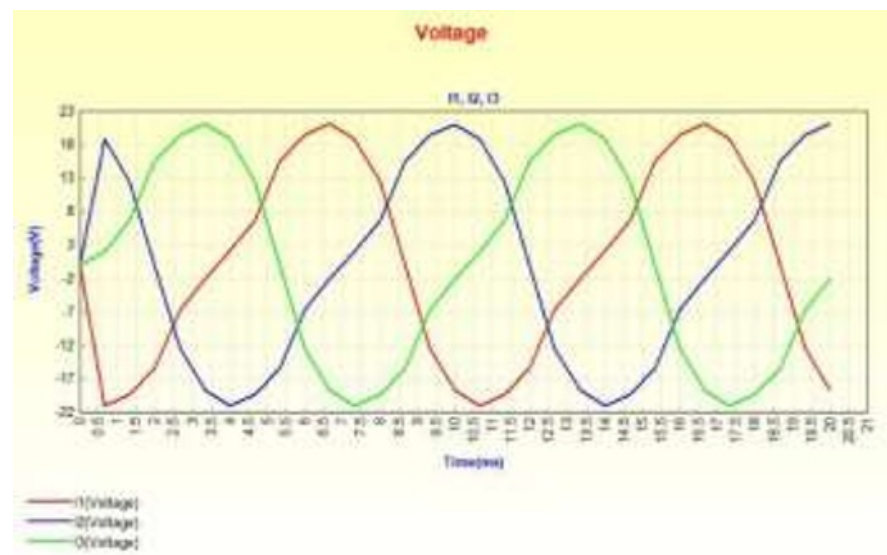

Fig. 6. Wavefrom phase voltage of PMSG.

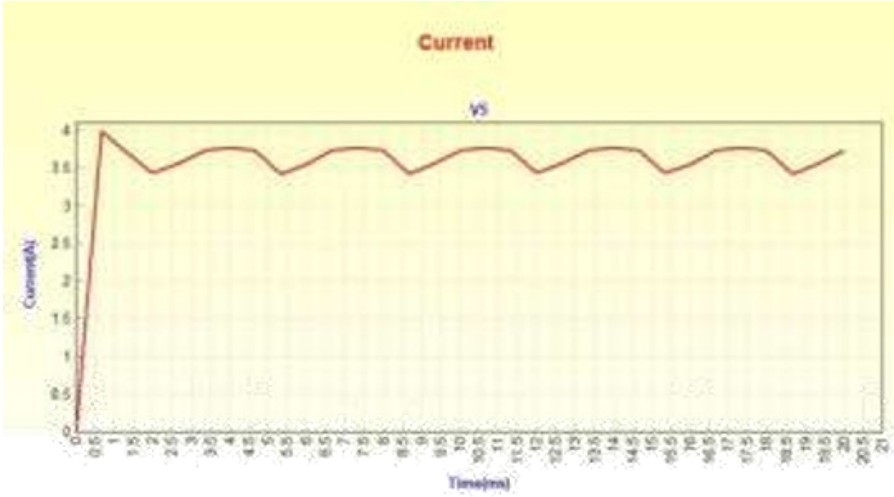

Fig. 7. Wavefrom of current PMSG.

Test results at a nominal speed of $500 \mathrm{rpm}$, generated PMSG maximum phase voltage with a value $22.5 \mathrm{~V}$ and maximum phase voltage with a value $38.84 \mathrm{~V}$. Sinusoid waveform display results of the MagNet software simulation as shown in Figure 6. Test results of the comparison of output phase-phase voltage due to the difference in rotational speed of the rotor as shown in Table 3. Based on data in Table 3 explains that the higher the rotational speed of the generator rotor, the greater the output voltage. For the load generator simulation, it is given a resistor load of $10 \Omega$, and the generator will rotate at a speed of 500 $\mathrm{rpm}$. Before being given a load resistor, the output voltage of the generator will be rectified first using six diodes (full wave rectifier). In this simulation voltage and current are obtained by the dc side. Furthermore, this data will also be used to see the output of the generator. Waveform display results of the MagNet software simulation under load condition as shown in Figure 7. It shows the dc current value after being directed from the generator output. The waveform shows that the maximum value of dc current is $3.99 \mathrm{~A}$. 
Table 3. Stator and rotor design specification.

\begin{tabular}{|c|c|c|}
\hline No & Speed (rpm) & Phase-phase maximum voltage (V) \\
\hline 1 & 100 & 8.14 \\
\hline 2 & 200 & 16.06 \\
\hline 3 & 300 & 24.39 \\
\hline 4 & 400 & 31.83 \\
\hline 5 & 500 & 38.84 \\
\hline
\end{tabular}

\section{Conclusion}

This research has shown that the hydrological model and GIS can be implemented to the spatially Based on the simulation design of a $500 \mathrm{~W}$ three phase permanent magnet generator which has 18 slots and 12 poles, it can be concluded as follows: (i) Simulation of permanent magnet synchronous generator 18 slots 12 poles, obtained inter-phase output voltage of $38.84 \mathrm{~V}$, in the no-load test with rotation of $500 \mathrm{rpm}$; (ii) The effect of the generator rotational speed variation is directly proportional to the voltage generated by the generator; and (iii) Under load conditions, the generator simulation obtained the maximum dc current value is $3.99 \mathrm{~A}$.

\section{References}

1. C. He, T. Wu, CES Transactions on Electrical Machines and Systems, 3,1: 94-100(2019).

https://ieeexplore.ieee.org/document/8677377

2. G. Zhu, X. Liu, L. Li, H. Chen, J. Zhu, CES Transactions on Electrical Machines and Systems, 3,2:204-209(2019).

https://ieeexplore.ieee.org/document/8766943

3. Y. Liu, Z. Zhu, C. Gan, S. Brockway, C. Hilton, The Journal of Engineering, 17:4585-4589(2019).

https://digital-library.theiet.org/content/journals/10.1049/joe.2018.8202

4. D. Lim, J. Ro, IEEE Access, 7:85139-85145(2019).

https://ieeexplore.ieee.org/abstract/document/8744197

5. P.F.C. Gonçalves, S.M.A. Cruz, A.M.S. Mendes, The Journal of Engineering, 2019,17:4532-4536(2019).

https://ieeexplore.ieee.org/abstract/document/8737118

6. R.M. Sallinen, T. Messo, P. Rasilo, J. Rekola, The Journal of Engineering, 18:51975201(2019).

https://digital-library.theiet.org/content/journals/10.1049/joe.2018.9332

7. P. Jaen-Sola, A.S. McDonald, Structural analysis and characterization of radial flux PM generators for direct-drive wind turbines, 3rd Renewable Power Generation Conference, (Naples, Italy, 2014). p. 1-6.

https://ieeexplore.ieee.org/document/6993259

8. M.H. Qais, H.M. Hasanien, S. Alghuwainem, The Journal of Engineering, 2017,13:1750-1754(2017).

https://digital-library.theiet.org/content/journals/10.1049/joe.2017.0595 
9. R.H. Eckstein, T.B. Lazzarin, I. Barbi, Proposed power and control system for small scale wind turbines connected to the grid, 3rd Renewable Power Generation Conference, (Naples, Italy, 2014). p. 1-6.

https://ieeexplore.ieee.org/document/6993229

10. F. Deng, D. Liu, Z. Chen, P. Su, Chinese Journal of Electrical Engineering, 3,1:5162(2017).

https://ieeexplore.ieee.org/document/7961322

11. D. Zhou, F. Blaabjerg, T. Franke, M. Tønnes, M. Lau, IEEE Transactions on Industrial Electronics, 62,10:6575-6584(2015). https://ieeexplore.ieee.org/document/7151832

12. X. Bracke, J.D.M. De Kooning, J. Van de Vyver, L. Vandevelde, Effective capture of wind gusts in small wind turbines by using a full active rectifier, 3rd Renewable Power Generation Conference, (Naples, Italy, 2014). p. 1-6.

https://ieeexplore.ieee.org/document/6993228 